catheter lab) and the development of pulseless electrical activity (PEA) at any time (table 2$)$. Culprit vessel $(p=0.810)$, STelevation at presentation, and age were not significantly associated with 30 day mortality $(p=0.426$ and $p=0.085$ respectively). Furthermore, there was no difference in mortality between those who underwent PCI and those who received angiography alone.

Conclusion OHCA constituted $0.9 \%$ of activity during the period of review. There were significant correlations between 30 day mortality and several biochemical and clinical markers available at presentation. The use of these markers may be of use in triaging patients who are likely to benefit from interventional procedures.

\section{THE INFLUENCE OF COLLATERAL REGRESSION POST CORONARY CHRONIC TOTAL OCCLUSION (CTO) PERCUTANEOUS CORONARY INTERVENTION (PCI) ON DONOR VESSEL CORONARY PRESSURE-DERIVED MEASUREMENTS}

${ }^{1}$ Shah Mohdnazri* ${ }^{1}$ 'Firas Al-Janabi, ${ }^{1}$ Grigoris Karamasis, ${ }^{2}$ James Hampton-Till, ${ }^{3}$ Rasha AlLamee, 'Jason Dungu, ' ${ }^{1}$ Swamy Gedela, ${ }^{1}$ Kare Tang, ${ }^{1}$ Paul Kelly, ${ }^{3}$ Justin Davies, ${ }^{1}$ John Davies, ${ }^{1}$ Thomas Keeble. ${ }^{1}$ Essex Cardiothoracic Centre; ${ }^{2}$ Anglia Ruskin University; ${ }^{3}$ Imperial College London

\subsection{6/heartjnl-2017-311726.23}

Background There is strong evidence of FFR guided treatment in multi-vessel disease. The presence of a concomitant CTO may influence the FFR measurement in donor vessel as suggested in previous studies and reports. This has an important implication on clinical decision making for complete revascularisation in patients with chronic total occlusion. We sought to investigate the influence of collateral regression after successful CTO recanalisation on donor vessel pressure-derived indices.

Methods The study participants were patients with angina who had RCA CTO. 28 out of 34 consecutive patients underwent successful PCI to RCA CTOs during the study period and completed the follow study (at 3 months post CTO PCI) were included in this analysis. Coronary pressure-derived indices (resting PD/PA, iFR and FFR) were measured pre and post successful RCA CTO PCI in donor vessels and at follow up procedures.

Results The mean age was 62.38 years. The mean estimated CTO duration was 238.72 weeks and CTO length was $32.44 \mathrm{~mm}$. 25 patients had ischaemia and or viability in the RCA territory assessed with cardiac MRI. LAD was the major donor vessel in 24 patients and LCX was the minor donor vessel in 4 patients. Percent stenosis on QCA in the major and minor donor vessel were $40.6 \%$ and $35.1 \%$ respectively. The mean resting $\mathrm{Pd} / \mathrm{Pa}$, iFR and FFR pre and post RCA CTO PCI and at follow-up procedures in major donor vessel were $(0.893,0.862,0.764),(0.907,0.886,0.753)$ and $(0.918$, $0.901,0.787)$ respectively. The mean resting $\mathrm{Pd} / \mathrm{Pa}, \mathrm{iFR}$ and FFR pre and post RCA CTO PCI and at follow-up procedures in minor donor vessel were $(0.979,0.966,0.890)$, $(0.983,0.979,0.880)$ and $(0.981,0.974,0.898)$ respectively. The changes in coronary pressure-derived indices pre and post RCA CTO PCI and at follow up procedures are summarised in table 1. In major donor vessel, there was significant changes in the difference between follow up and pre-CTO PCI values for $\mathrm{Pd} / \mathrm{Pa}$, iFR and FFR values ( $\mathrm{p}$ values 0.006 , 0.003 and 0.047 respectively). There was also significant

Abstract 23 Table 1 Coronary pressure-derived indices pre and post RCA CTO PCI and at follow up procedures (FU:Follow-up, PCl: Percutaneous Coronary Intervention, FFR: Fractional Flow Reserve, СTO: Chronic Total Occlusion)

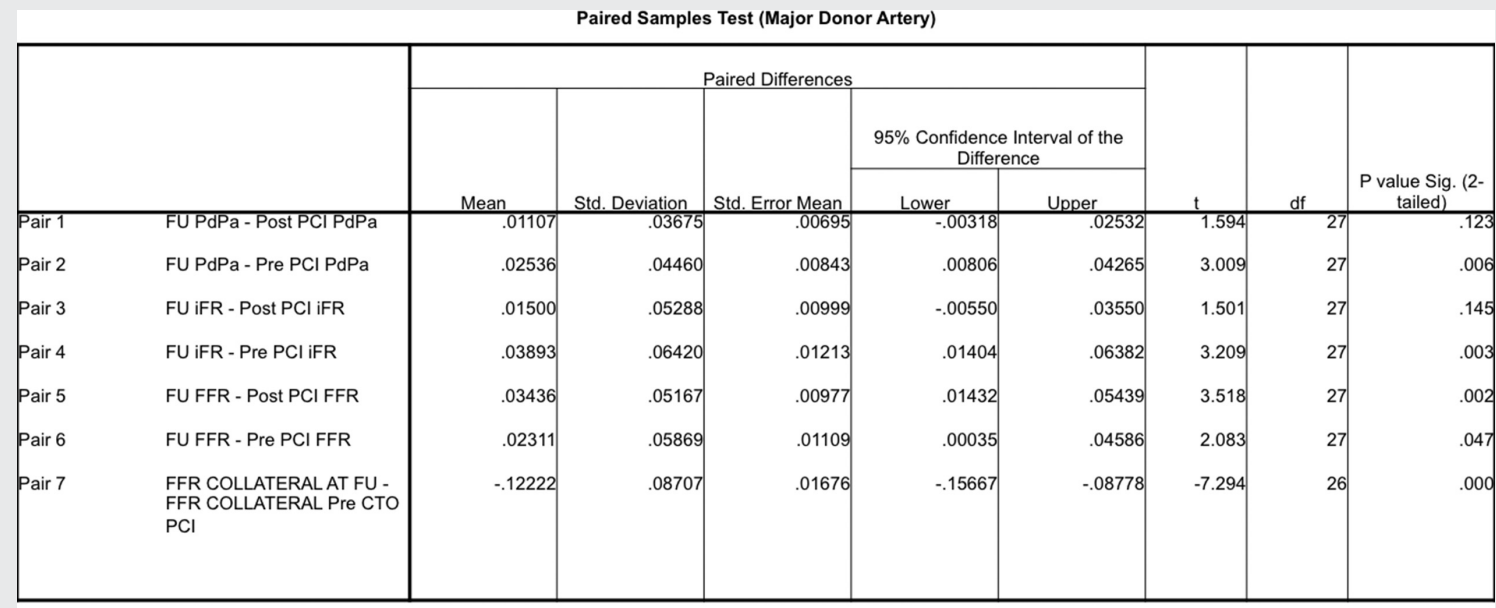

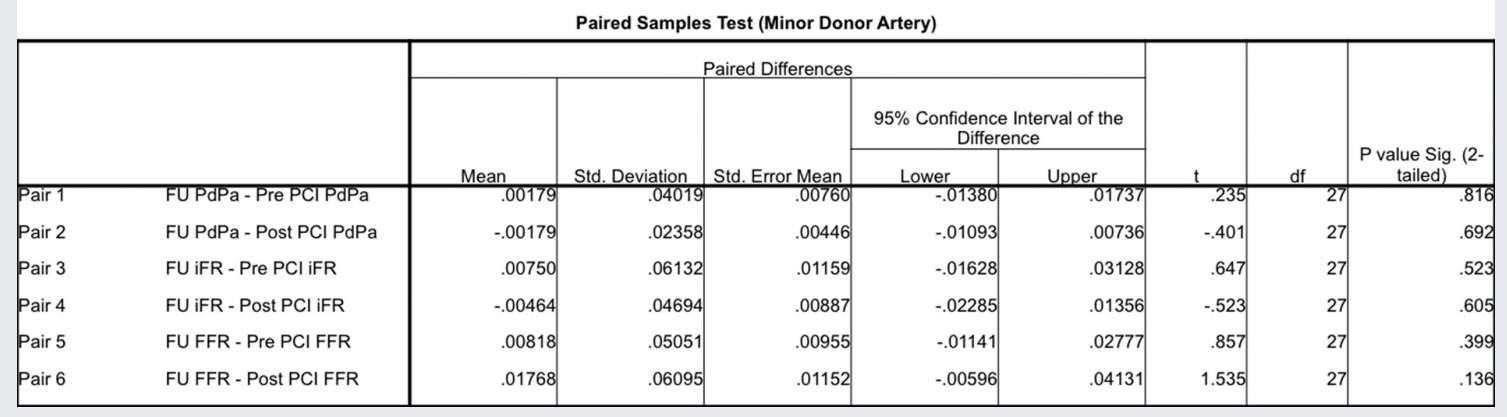


change in the difference between follow up and post-CTO PCI FFR value (P value 0.002). FFR collateral reduced significantly at follow-up ( $\mathrm{p}$ value 0.000 ).

Conclusion Successful recanalisation of a RCA CTO results in increase in major donor vessel coronary pressure-derived indices at follow up procedure associated with the regression of collateral function. In patients with multi-vessel disease, the expected change and the optimal timing to perform PCI in donor vessel should be considered when planning multi-vessel revascularisation in this setting.

\section{THE PHYSIOLOGICAL IMPACT OF CORONARY CHRONIC TOTAL OCCLUSION (CTO) PERCUTANEOUS CORONARY INTERVENTION (PCI) ON DONOR VESSEL CORONARY PRESSURE-DERIVED MEASUREMENTS AND THE INFLUENCE OF COLLATERAL CIRCULATION}

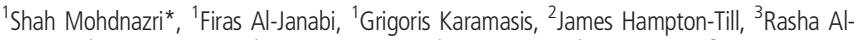
Lamee, ${ }^{1}$ Jason Dungu, ${ }^{1}$ Swamy Gedela, ${ }^{1}$ Kare Tang, ${ }^{1}$ Paul Kelly, ${ }^{3}$ Justin Davies, ${ }^{1}$ John Davies, ${ }^{1}$ Thomas Keeble. 'Essex Cardiothoracic Centre; ${ }^{2}$ Anglia Ruskin University; ${ }^{3}$ Imperial College London

\subsection{6/heartjnl-2017-311726.24}

Background There is strong evidence of FFR guided treatment in multi-vessel disease. Multi-vessel disease is present in up to $66 \%$ of patients with CTO in a large registry analysis. The presence of a concomitant CTO may influence the FFR measurement in donor vessel as suggested in previous studies and reports. This has an important implication on clinical decision making for complete revascularisation in patients with chronic total occlusions. There is a growing interest on the influence of collateral circulation, flow, amount of myocardium supplied by donor artery to a CTO and the impact of CTO revascularisation on donor vessel pressure-derived indices. We sought to investigate the physiological impact of CTO recanalisation on donor vessel pressure-derived indices.

Methods The study participants were patients with angina who had RCA CTO. 34 out of 40 consecutive patients underwent successful PCI to RCA CTOs during the study period were included in the analysis. Coronary pressurederived indices (resting $\mathrm{Pd} / \mathrm{Pa}$, iFR and FFR) were measured pre and post successful RCA CTO PCI in donor vessels. Donor vessel characteristics were graded using the Rentrop and colloateral connexion grading classification.

Results The mean age was 61.76 years. The mean estimated CTO duration was 238.72 weeks and CTO length was $32.44 \mathrm{~mm} .31$ patients had ischaemia and or viability in the RCA territory assessed with cardiac MRI.

LAD was the predominant donor vessel in 30 patients and LCX was the minor donor vessel in 4 patients. Percent stenosis on QCA in the predominant and minor donor vessel were $41.43 \%$ and $35.05 \%$ respectively. The angiographic details are as outlined in table 1 . The mean resting $\mathrm{Pd} / \mathrm{Pa}, \mathrm{iFR}$ and FFR pre and post RCA CTO PCI in major donor vessel were $(0.891,0.858,0.759)$ and $(0.903,0.882,0.746)$ respectively. $\mathrm{iFR}$ in the major donor vessel increased from 0.858 to 0.882 (difference, $0.02412(0.00573$ to 0.04250$) ; p=0.012)$. There were no significant difference in resting $\mathrm{Pd} / \mathrm{Pa}$ and $\mathrm{FFR}$ pre and post CTO PCI $(\mathrm{p}=0.109$ and $\mathrm{p}=0.388$ respectively).

The mean resting $\mathrm{Pd} / \mathrm{Pa}$, iFR and $\mathrm{FFR}$ pre and post RCA CTO PCI in minor donor vessel were $(0.982,0.969,0.894)$ and $(0.985,0.979,0.885)$ respectively. There were no significant difference in resting $\mathrm{Pd} / \mathrm{Pa}, \mathrm{iFR}$ and $\mathrm{FFR}$ pre and post CTO PCI in minor donor vessel $(p=0.534, p=0.152$, $\mathrm{p}=0.183$ respectively).

The mean collateral FFR was 0.310 . The mean total ischaemic burden on baseline cardiac MRI in RCA territory was $12.6 \%$.

Conclusion Successful recanalisation of a RCA CTO results in increase in iFR but no significant difference was seen in resting $\mathrm{Pd} / \mathrm{Pa}$ and FFR pre-RCA CTO PCI and immediately post recanalisation in predominant donor vessel. Complete collateral regression was not observed in all patients immediately post RCA CTO PCI and this may account for the non-significant change in FFR values.

\section{Abstract 24 Table 1 Angiographic Characteristics}

\begin{tabular}{|c|c|c|c|}
\hline \multicolumn{4}{|c|}{ Angiographic Characteristics } \\
\hline & & $\mathrm{n}$ & $\%$ \\
\hline Сто Vessel & RCA & 34 & 100 \\
\hline \multirow{2}{*}{$\begin{array}{l}\text { Predominant donor } \\
\text { vessel }\end{array}$} & LAD & 30 & 88 \\
\hline & $L C X$ & 4 & 12 \\
\hline \multirow{5}{*}{$\begin{array}{l}\text { Overall Rentrop } \\
\text { Classification grading }\end{array}$} & & Pre CTO $\mathrm{PCl}(\mathrm{n})$ & Immediately Post CTO PCl (n) \\
\hline & 0 & 0 & 3 \\
\hline & 1 & 0 & 25 \\
\hline & 2 & 2 & 6 \\
\hline & 3 & 32 & 0 \\
\hline \multirow{4}{*}{$\begin{array}{l}\text { Overall Collateral } \\
\text { Connection Classification } \\
\text { grading }\end{array}$} & 0 & 0 & 23 \\
\hline & 1 & 3 & 10 \\
\hline & 2 & 22 & 0 \\
\hline & 3 & 9 & 1 \\
\hline
\end{tabular}

